\title{
A afetividade no contexto de conclusão da educação básica
}

Márcia Maria Rodrigues Tabosa Brandão* Dayse Carla Rodrigues de Macedo Mattos ${ }^{* *}$

\section{Resumo:}

Este artigo tem como objetivo analisar a repercussão de uma ação educativo-pedagógica, fundada pela afetividade no processo formativo dos estudantes de turmas da 3 a série do Ensino Médio do Colégio de Aplicação (CAp) - UFPE. O trabalho resulta de uma pesquisa do tipo estudo de caso, tendo como procedimentos/instrumentos para coleta de dados: entrevista e observação participante com interpretação pela técnica da análise de conteúdo. Reflete-se acerca da afetividade na relação pedagógica como viabilizadora do reconhecimento e da vivência desse período formativo com fim em si mesmo, ou seja, o desenvolvimento do pensar, sentir e agir. Evidencia-se a necessidade de uma educação que nos permita sonhar e criar novos valores, idealizar e configurar novas visões de mundo mais coerentes e sustentáveis em relação ao desenvolvimento da vida e promover a aprendizagem abrangendo as diferentes dimensões humanas.

\section{Palavras-chave:}

Finalização da educação básica. Processo formativo. Afetividade.

\begin{abstract}
:
This article aims to analyze the repercussion of an educational-pedagogical action based on affectivity in the formative process of students of classes in the 12th grade of High School at Colégio de Aplicação (CAp) - UFPE. The work is the result of a case study research with the following procedures/ instruments for data collection: interview and participant observation with interpretation using the content analysis technique. The data made it possible to reflect on the affectivity in the pedagogical relationship as enabling the recognition and the experience of this formative period as an end in itself, that is, the development of thinking, feeling and acting. It became evident the need for an education that allows us to dream and create new values, idealize and configure new world views that are more coherent and sustainable in relation to the development of life, and promote learning covering different human dimensions.
\end{abstract}

\section{Keywords:}

Completion of basic education. Formative process. Affectivity.

\footnotetext{
* Mestra em Educação pela UFPE, pedagoga no Colégio de Aplicação da Universidade Federal de Pernambuco - UFPE. E-mail: marcia.brandao@ufpe.br. ORCID iD: http://orcid.org/0000-0001-8889-8975.

** Residência em Saúde Mental pela Secretaria de Saúde do Estado de Pernambuco, psicóloga no Serviço de Psicologia Aplicada SPA da UFPE. E-mail: daysecmattos@yahoo.com.br. ORCID iD: http://orcid.org/0000-0001-8434-3606.
} 


\section{Introdução}

Em nossa atuação no Serviço de Orientação Educacional (SOE) no Colégio de Aplicação da Universidade Federal de Pernambuco (CAp-UFPE), junto a adolescentes em processo de conclusão do ciclo de aprendizado na educação básica, foi possível identificar a intensificação de uma gama de emoções e sentimentos por parte dos estudantes devido às suas expectativas com relação à construção de um projeto de vida envolvendo a escolha de uma profissão.

Durante o contato com os discentes, observamos que eles frequentemente assumiram estruturar suas trajetórias profissionais com o objetivo de atender às expectativas do meio social, mesmo que tivessem de abdicar de seus interesses quando estes não lhes permitissem atingi-las. Ao fazer tal leitura, percebemos a inclinação dos estudantes a ingressarem em cursos de graduação frequentemente associados à aquisição de status e à valorização do mercado, o que sustenta uma concepção de Ensino Médio como fase de preparo do sujeito para o ingresso no Ensino Superior, que, por sua vez, permitiria que ele ocupasse patamares mais favoráveis no mercado de trabalho e no atingimento ou na manutenção de uma condição socioeconômica mais estável. Entretanto, essa noção reduz o nível médio da escolarização à preparação para o vestibular (SPARTA; GOMES, 2005).

Também foi observado que essas escolhas, baseadas nas aspirações à continuidade do processo de aprendizagem em cursos acadêmicos situados em instituições de Ensino Superior renomadas, têm levado os estudantes do CAp-UFPE a, recorrentemente, despender uma quantidade excessiva de horas de estudo extraescolar, especialmente em cursinhos preparatórios para o Exame Nacional do Ensino Médio (ENEM). Esse quadro refletia em pouca atenção ao tempo de descanso, de lazer e de cuidado com o corpo, provocando muitas vezes prejuízo às interações sociais e familiares desses discentes.

Há, nesse contexto contemporâneo, um grande estímulo à competição e o reforço de que o conteúdo apreendido durante toda a trajetória de estudos é insuficiente para se obter êxito em ingressar no Ensino Superior, frente à preferência por cursos acadêmicos mais procurados, como também pela pretensão de ingresso em instituições de ensino bastante concorridas, devido ao reconhecimento da qualidade do ensino ofertado. Não obstante, percebe-se cobrança de resultado positivo por parte tanto das famílias como dos próprios estudantes, o que faz gerar nos jovens um sentimento de impotência com relação ao desafio representado pela prova, como também, não raro, crises de ansiedade. Assim, a cultura de cursinhos no contraturno da escola se estabelece, sem a identificação dos danos causados pela cobrança de alto desempenho.

Cumpre destacar que o foco no acúmulo de informações compartimentadas, visando ao sucesso em certas áreas do conhecimento, com a chancela das famílias, reforça o padrão educacional de pensamento linear e simplificador, exclusivamente intelectual, como meio de desenvolver os talentos e as especialidades. E na lógica racional e fragmentada de aprendizado, o receio de errar e de não atingir os objetivos projetados causa nos adolescentes o sofrimento de ter fracassado. Mesmo com esse custo de desgaste emocional, é como se o fim justificasse os meios. Para D’ávila e Soares (2003), a família, de modo geral, participa desse processo ao modificar hábitos e, muitas vezes, abstém-se de sair e de se divertir para não prejudicar a rotina de estudos dos filhos. As autoras ainda salientam que os pais criam expectativas e projetos de vida para os filhos, o que também é gerador de angústia e de ansiedade na adolescência.

Esse panorama nos revela que os estudantes do CAp-UFPE e suas famílias construíram expectativas e críticas quanto à instituição: por um lado, por reconhecê-la como possibilidade de ascensão social e econômica e, por outro, pelo fato de identificá-la como via efetiva na preparação dos estudantes para ingressar no Ensino Superior. Posto isto, fica perceptível que o projeto educacional de muitas famílias não se alinha à proposta pedagógica definida pelo colégio no que se refere à produção contextualizada do conhecimento e do aprendizado rico em significados, na perspectiva da formação humana, pautada em valores, de integração do sujeito em desenvolvimento. Essa afirmação nos remete ao Projeto Pedagógico do Colégio de Aplicação da UFPE (2016), o qual define que o conjunto das práticas administrativas e pedagógicas projetadas para seus estudantes tem por finalidade a formação integral do sujeito. Nesse sentido, fomenta-se a construção do conhecimento associado à realidade vivida por ele, abarcando a formação conceitual, atitudinal e proce- 
dimental. Além disso, o documento suscita a autonomia intelectual, o pensamento crítico e reflexivo, como também a postura solidária e tolerante na perspectiva da subjetividade e do reconhecimento da diversidade.

Tal posicionamento, muitas vezes, é demonstrado com o investimento realizado pelas famílias para o ingresso de seus filhos no $6^{\circ}$ ano do Ensino Fundamental no CAp-UFPE, que se projeta no cenário nacional como uma escola de excelência, sobretudo pelos resultados obtidos pelos seus discentes no ENEM, apresentando desde 2014 a maior nota entre as escolas públicas no estado de Pernambuco (UFPE, 2019; BOTLER; SILVA, 2019; APLICAÇÃO..., 2020). Vale frisar que, ainda crianças, na faixa etária entre 9-12 anos, os estudantes já são submetidos a extensas cargas horárias de estudo e aulas de cursinho preparatório extenuante, a fim de vencer o seu primeiro concurso público. Porém, mesmo que atribuam tamanho valor à escola ao investirem no preparo de seus filhos para que eles possam ingressar na instituição, a confiança apresentada pelas famílias dos estudantes não as isenta de fomentarem a cultura de complementação das vivências escolares por meio de aulas no contraturno em cursinhos pré-vestibulares.

No que tange ainda à fase de finalização da educação básica vivida pelo adolescente e às novidades que sucedem o término desse ciclo, Mattos e Brandão (2018) relatam o quanto tal momento pode afetar e fragilizar os estudantes devido ao receio da não aprovação no ENEM e que a possibilidade de eles se sentirem acolhidos pela(s) figura(s) de apego é incentivadora para que cada um prossiga com seu(s) projeto(s), além de colaborar para a formação de valores por esses sujeitos cidadãos.

Adita esse entendimento Morin (2012) quando declara que um ambiente favorável à educação requer, notadamente, afetos de boa energia. Eles promovem a ação humana, suscitando o interesse para a aprendizagem, devido a sua influência no desenvolvimento, nas expressões de inteligência e no conhecimento. Para tanto, o autor considera o ser humano na qualidade de ser que pensa, sente e anseia e reconhece a cognição não sobreposta à afetividade, que, por sua vez, não se configura mais relevante que a cognição. Em oposição, uma educação sem afetividade desertifica a relação pedagógica.

Diante dessas constatações, alguns questionamentos se configuram essenciais: como o professor analisa o momento de finalização da educação básica vivenciado pelos estudantes? O que pensa o professor acerca da repercussão da afetividade no desenvolvimento de sua prática nesse contexto? Como promover ambientes de aprendizagem que colaborem para o desenvolvimento pleno do estudante?

Em função do exposto, este artigo objetiva analisar a repercussão de uma ação educativo-pedagógica, fundada pela afetividade, no processo formativo dos estudantes de turmas da $3^{a}$ série do Ensino Médio do CAp-UFPE.

\section{Um olhar sobre o ingresso no CAp-UFPE}

O Colégio de Aplicação oferta vagas a estudantes do $6^{\circ}$ ao $9^{\circ}$ ano do Ensino Fundamental e de todo o Ensino Médio. Desde a sua fundação, essa instituição vivenciou formas distintas de selecionar o público excedente interessado em ingressar no colégio, e, na atualidade, o processo seletivo, ainda bastante concorrido, se dá através das provas de Português e Matemática.

Em conformidade com o Projeto Pedagógico do Colégio de Aplicação da UFPE (2016), a cada ano, são ofertadas 55 vagas para o $6^{\circ}$ ano do Ensino Fundamental e, em média, 1.700 candidatos realizam as referidas provas, evidenciando, assim, uma experiência de competição marcante para estudantes com tão tenra idade. No tocante aos demais anos e séries, também há seleção por provas, em virtude de vagas por evasão ou retenções.

De acordo com Almeida (2014), em sua pesquisa sobre representações sociais do CAp-UFPE por seus estudantes e os responsáveis deles atreladas às perspectivas de futuro, o valor simbólico atribuído ao colégio justifica o empreendimento de esforços ${ }^{1}$ para se obter sucesso no processo seletivo que acolhe os estudantes mais bem preparados para vivenciar a ação pedagógica concebida e desenvolvida pela instituição.

1. Dentre as estratégias empreendidas, salientamos: cursinhos preparatórios, definição de horários de estudo direcionados à antecipação da matéria e resolução de provas de seleções anteriores. Entretanto, constataram-se contextos em que foi necessário maior esforço para superar defasagens de escolarização. 
Ainda segundo a referida autora, para esses sujeitos, o colégio faz parte de uma lista de possibilidades que se adequa à perspectiva de êxito futuro e realização profissional das famílias para seus filhos, interiorizada pela maioria deles. Para tanto, esse projeto requer acessar a melhor base educacional para encontrar-se em condições de ocupar os cursos universitários mais concorridos, bem como disputar cargos e posições privilegiadas no mercado de trabalho. Sendo assim, a escolha do colégio se dá, dentre alguns dos aspectos, devido aos resultados expressivos nas avaliações externas ${ }^{2}$, às propostas inovadoras, ao incentivo à pesquisa, à ambientação universitária e ao ensino que promove e garante a formação e humanização (ALMEIDA, 2014).

Ademais, a referenciada autora revela que os pais ou responsáveis pelos alunos consideram estar a instituição na contramão da educação mercadológica e fazem críticas ao mercado escolar acirrado, todavia, apontam ter inscrito os filhos nos cursinhos, se sujeitando à dinâmica competitiva imposta, análoga àquela por que passam os estudantes em fase final da educação básica. Por mais que a proposta educacional da instituição não estimule a competitividade, o sentimento de pertença a um grupo seleto identificado como alunos de excelência robustece a divisão entre quem sabe e quem não sabe e de poder ser o que quiser (ALMEIDA, 2014).

Fazem um contraponto a esse contexto Botler e Silva (2019) ao afirmar que, no decurso da história do CAp-UFPE, o processo seletivo adotado se configurou em mecanismo seletivo, classificatório e eliminatório. Isso porque o colégio adotou como critério exclusivo o desempenho escolar, não levando em conta que a aprovação dos estudantes se dá tanto pelo mérito individual como pelo engajamento das famílias devido ao capital econômico dispensado no percurso da escolarização dos filhos. Como resultado, as autoras identificam a injustiça advinda da seletividade acadêmica e social através desse processo seletivo, que não colaborou com a democratização da escola pública.

Cabe ressaltar que, em resposta favorável às políticas afirmativas no sentido de assegurar a igualdade de condições para o acesso e a permanência de estudantes no CAp-UFPE, foram realizadas alterações em seu processo seletivo para viabilizar o acesso dos estudantes em vulnerabilidade social à instituição, com a implementação de cotas, através da Resolução ${ }^{\circ}$ 14/2016. Sendo assim, o ingresso via cotas sociais passou a destinar 50\% das vagas para estudantes oriundos de escolas públicas a partir da seleção de 2017 (UFPE, 2016).

Para além da forma do acesso, é importante pensar nesse sujeito em desenvolvimento, que passa por um período de transição exatamente na fase que compreende meados do Ensino Fundamental. Não raro, é para muitos estudantes uma condição difícil e estressante, tendo em vista ser uma época marcada por mudanças: no indivíduo, na escola e na família ao mesmo tempo. Tais mudanças incluem a puberdade e, por conseguinte, as transformações no corpo e a percepção da imagem corporal; aumento da responsabilidade com as demandas escolares e de cuidado pessoal, devido à diminuição da dependência dos pais; à estrutura física da escola maior e mais impessoal; à passagem da referência de um professor para vários professores; à saída de um grupo pequeno de colegas para um grupo maior; ao olhar mais voltado para o desempenho e os resultados (SANTROCK, 2014).

Combinado a isso tudo, há a quebra da lógica de que todos frequentavam a escola no bairro onde residem, requerendo para alguns estudantes deslocamentos longos, além de favorecer o sentimento de estarem crescidos e o ganho de autonomia por não terem o monitoramento direto dos pais. Exige-se, assim, toda uma adequação da rotina familiar e de investimento de tempo nas novas demandas escolares e, para a escola, o grande desafio de promover o ensino com esse mosaico de realidades.

\section{Percurso metodológico}

Este artigo apresenta parte dos resultados de uma pesquisa qualitativa, do tipo estudo de caso, realizada no período de 2018 a 2020. Segundo Yin (2005, p. 20), o estudo de caso "surge do desejo de se compreender fenômenos sociais complexos", permitindo, pois, "preservar as características holísticas e significativas dos acontecimentos da vida real".

2. Conforme a UFPE (2019), o Colégio de Aplicação é destaque no ENEM devido ao excelente resultado obtido pela escola em 2018. 
Para esse fim, coletamos os dados através dos seguintes procedimentos/instrumentos: entrevistas e observação participante. Segundo Duarte (2004), a entrevista oportuniza mapear práticas, valores e crenças de contextos sociais, evidenciando como os sujeitos percebem e significam a sua realidad. De acordo com Marques (2016), a observação participante dá pistas ao pesquisador sobre como direcionar a pesquisa, bem como permite a compreensão aprofundada a respeito dos processos educativos e de que modo atuam os sujeitos nesse contexto.

Os dados foram analisados à luz da análise de conteúdo, reconhecida com um conjunto de técnicas de análise das comunicações que visa inferir sobre conhecimentos referentes às condições de produção e recepção do conteúdo das mensagens (BARDIN, 2011).

No tocante à escolha dos sujeitos, foram selecionados aqueles que tiveram avaliações acerca do processo pedagógico ${ }^{3}$ realizadas com destaque para o estabelecimento de vínculo e ressonância afetiva com uma turma da $3^{\text {a }}$ série, no âmbito das reuniões do conselho de classe ${ }^{4}$, ao longo do ano letivo de 2017. O recorte estabelecido para a pesquisa compreende a interação com dois professores, aos quais nos referiremos como Professor 1 (PROF. 1) e Professora 2 (PROF. 2).

\section{Resultados e discussões}

A finalização da educação básica marca um período de expectação por parte dos estudantes acerca da continuidade das experiências de formação, bem como do ingresso no mercado de trabalho. Tal desfecho suscita abertura para novos projetos de vida e, ao mesmo tempo, revela as agruras de elaboração do fechamento desse ciclo de vida: o fim da fase de adolescência para a entrada na vida adulta. Vejamos como os professores percebem o contexto escolar contemporâneo e dizem de suas práticas e dos desafios encontrados: "Acredito que ainda deixamos lacunas quanto ao desenvolvimento de competências socioemocionais e isso é bem nítido nas posturas dos estudantes frente a conflitos externos e internos, tomada de decisão quanto ao mercado de trabalho e até mesmo a insegurança ao se desligarem do colégio" (PROF. 2).

A fala da Professora 2 evidencia uma percepção por parte dela a respeito das "lacunas quanto ao desenvolvimento de competências socioemocionais", principalmente no enfrentamento do estresse gerado pela proximidade da prova do vestibular, mas também pelos conflitos oriundos da escolha profissional e do fechamento de ciclo da educação básica. Não raro, observamos que, de modo geral, os professores do CAp-UFPE têm sido demandados a assumir o papel de dar suporte aos estudantes, através de intervenções projetadas de modo individual ou em parceria com a equipe pedagógica, visando ajudar esses jovens tomados pelo cansaço, irritabilidade e choro fácil, problemas tão evidentes na rotina escolar. Rosenburg (2006) reforça a afirmação expressa pela professora entrevistada, destacando que é urgente a tomada de consciência e sensibilização acerca desse quadro tanto pelos profissionais da educação quanto pelos profissionais da saúde, no sentido de contribuir para a diminuição da ansiedade apresentada pelos jovens.

Reconhecemos a relevância do trabalho docente nesse processo, pelo fato de ele poder ser formador e transformador da realidade, contudo, é preciso considerar que há aspectos internos e externos ao âmbito educacional que atravessam e impactam o momento vivido por esses estudantes e que refletem nesse contexto. Nesse sentido, Nascimento e Hetkowski (2009, p. 301), esclarecem que

[...] a resposta para essas questões não pode ser encontrada, a não ser na compreensão da sociedade contemporânea que está passando por intensas transformações culturais, políticas, sociais e econômicas que direta ou indiretamente definem os rumos da formação e do trabalho do professor, conforme necessidades educacionais colocadas em cada momento histórico e contexto social.

3. A análise desses documentos pode ser acessada em "Conselho de classe e o lugar do afeto na relação educador e educando". Disponível em: https://www.editorarealize.com.br/editora/anais/conedu/2018/TRABALHO_EV117_MD1_SA1_ID10012_16092018194615.pdf. Acesso em: 17 maio 2020.

4. Exclusivamente nos conselhos de classe de acompanhamento, há a participação dos estudantes. Nessas reuniões, professores e estudantes avaliam o processo pedagógico e, de acordo com a reflexão estabelecida, são propostos encaminhamentos pelos sujeitos participantes. 
Tal perspectiva é corroborada com a narrativa do outro docente, que demonstra reconhecer o impacto que as mudanças sociais e no mundo do trabalho ocasionam no âmbito educacional, admitindo a dificuldade apresentada pelas escolas em lidar com essa conjuntura que leva os estudantes à cobrança por alto desempenho.

O processo de conclusão da formação básica tem sido impactado por mudanças rápidas e profundas nos últimos anos. Desde a forma de ingresso na universidade, a preparação para o processo de seleção até os significados sociais que este momento ganhou ultimamente. [...] As escolas, seus professores e suas professoras estão com dificuldade em entender essa situação e apresentar novos caminhos a serem trilhados. Não conseguimos criar instrumentos para os/as estudantes e para a comunidade escolar enfrentarem as novas demandas. As escolas não conseguem efetivamente estabelecer quando o processo de formação básica termina. Hoje, ele parece ser finalizado à sua revelia. (PROF. 1).

Para tanto, consideramos essencial que os momentos de interação entre educadores e educandos consistam em manifestações do conhecer e da afetividade de maneira a colaborar para o aprendizado, para além da dinâmica escolar. Dessa forma, esse sujeito em construção vai se dando conta de suas escolhas e responsabilidades e definindo a sua identidade, a forma de ser, agir e sentir, a identificação com a área de atuação, as demandas a serem atendidas como cumprimento das disciplinas, a saída de casa, a relação interpessoal com pares, entre tantas outras questões. A articulação entre manifestações do conhecer e a afetividade nos remete às considerações de Pereira e Gonçalves (2010), ao afirmarem que o vínculo afetivo estabelecido entre professor e aluno em sala de aula contribui na formação de adultos que pensam de forma crítica o mundo que os cerca.

Outro aspecto a se acentuar diz respeito aos impactos ocasionados pelas tecnologias em potencializar as expectativas de futuro através de uma lógica solitária e com pouca possibilidade de troca. Vejamos o relato a seguir:

Mas há ainda outro ponto mais abrangente. Em todas as redes escolares, pública ou privada, e grupos sociais há uma aceleração própria do momento histórico. A vivência de tempo construída pelos bytes, pelas redes sociais inundam de possibilidades (e não de certezas) de futuro esses jovens. Há uma positividade em tudo, total e totalitária. Tudo estaria a alcance de todos por meio das redes sociais e pela ação individual nelas. Dentre várias consequências, destaco que tal cenário cria a desorientação e a ansiedade, ou seja, a antecipação de um futuro projetado pelos/pelas estudantes e pelos pais e mães que deve se tornar presente o mais rápido possível. (PROF. 1).

Podemos inferir com a fala do Professor 1 que a tecnologia configurou um modo de viver distante entre as pessoas, muitas vezes sem espaço de fala, sem qualquer tipo de possibilidade de tocar e ser tocado, para se tonarem seres ativos, que produzem resultados. A compreensão apresentada por esse entrevistado revela-se no quadro de desorientação e ansiedade, agravado pela pressão de antecipação do futuro, que ele reconhece estar acometendo os estudantes. Falar sobre esse esgotamento dá a dimensão do quanto essa escolha aniquila a vida social em favor dos projetos de futuro. Sendo assim, não há margem para tédio e nem contemplação tão necessários para a capacidade de se criar novas ideias e possibilidades. Tal enunciado remete ao pensamento trazido por Han (2015) no livro Sociedade do Cansaço. Esse autor destaca que o contexto contemporâneo vivido - a sociedade do desempenho - se apresenta excessivamente ativa, trazendo efeitos nos sujeitos, tais como cansaço e esgotamento. O teórico, aprofundando a discussão sobre esse fenômeno, declara que é como se os estados psíquicos fossem dominados pelo excesso de positividade, levando o sujeito a considerar que todas as metas são passíveis de serem alcançadas. As pessoas que se submetem à produtividade são denominadas "empresários de si mesmo" pelo autor por se autocobrarem constantemente, desenvolvendo fadiga e exaustão. Além disso, esse cansaço individualiza e isola, o que impossibilita a vida em comunidade e a existência de proximidade. 
A perspectiva de encerramento do Ensino Médio para o ingresso no Ensino Superior também vem revestida de grande estresse e mudanças. Conforme Mattos e Brandão (2018), a relação entre educador e educandos no período da educação básica é decisiva no sentido tanto de preparar os discentes para os projetos de futuro como de se conceber como sujeito no mundo. Nesse sentido, é significativo trazer a visão dos professores que integram esse processo e a repercussão afetiva na sua prática no contexto escolar:

Penso que afetividade é elemento chave para o envolvimento de todos e todas no processo educativo. É necessário que o professor mobilize os afetos, mas também promova essa mobilização por parte dos/ das estudantes. Isso me parece essencial para que os/as discentes se integrem na construção de sua formação escolar. (PROF. 1).

É interessante destacar o trecho em que o professor explicita o quanto a troca de afeto deve permear a rotina escolar e, se estiver presente no cotidiano dos discentes, engajá-los conjuntamente no processo de formação. É preciso estar com o outro, mas também se faz necessário ter o outro ao seu lado respondendo a essa interação. $\mathrm{O}$ afeto se dá entre os envolvidos e muda os sentidos do que está sendo produzido, inclusive na construção do conhecimento. Conforme Pratta (2008), o contexto educativo se constitui muito mais de relações, do que, efetivamente, conteúdos e métodos. Há uma necessidade nos indivíduos de serem olhados e tocados de maneira mais profunda do que se concebe na concepção mais literal dessas palavras, isto é, precisamos ser compreendidos no que tange às nossas emoções e anseios. Tal perspectiva se complementa com a fala seguinte:

Eu tento minimizar as distâncias no âmbito afetivo para impulsioná-los na construção do conhecimento. Percebi que uma relação de confiança e respeito entre professores e estudantes rebatem no maior engajamento nas atividades propostas em sala. Em especial, no último ano do Ensino Médio, um turbilhão de emoções de várias ordens se instala nos estudantes e a sensibilidade do professor é de fundamental importância neste momento tão crítico. Tenho tentado ajudar meus estudantes a encontrarem um equilíbrio para não deixarem de viver o que o colégio tem de melhor. (PROF. 2).

Destaca-se nesse relato o quanto a palavra "sensibilidade" se associa à capacidade de sentir, de se colocar no lugar do outro; ter um olhar atento para "minimizar as distâncias", contribuindo com o processo de aprendizagem. A "confiança" e o "respeito" parecem indicar a capacidade desse adulto, docente, ser alguém que ocupa o lugar de referência, a quem se possa recorrer quando se vive um "turbilhão de emoções" no momento crítico. Perceber-se e se colocar como alguém que pode dar apoio, andar junto ao estudante na busca de passar por essa fase com "equilíbrio", é uma possibilidade. Nesse sentido, ambos se colocam na relação com presença e reciprocidade. E, no âmbito desse entendimento, Souza e Bastos (2011) explicitam que os sentimentos dos professores também servem de apoio para o ensino, influenciando o modo como a mediação é feita em sala de aula.

Há ainda que se considerar a falta de sentido que a escola, no final da educação básica, passa a ter para os estudantes, que, estando voltados a se preparar para as provas do ENEM, não a percebem como um fim em si mesmo, isto é, a formação e desenvolvimento pessoal em interação com o grupo. Nessa perspectiva, o depoimento a seguir é ilustrativo dessa situação:

Para isso é necessário desenvolver a empatia. A aluna e o aluno do final do Ensino Médio que "abandonou" a escola para estudar nos cursos preparatórios ao ENEM, ou vai trabalhar ou se envolve em outras atividades está nos informando que a escola não tem mais sentido para ela/ele e suas demandas atuais de vida repletas de positividade, ansiedade, conectividade e solidão. [...] Acredito que na construção solidária e no desenvolvimento da empatia pode o professor e outros funcionários da escola entender melhor essas demandas e elaborar saídas, caminhos possíveis. As informações e os elementos para a construção desses novos caminhos estão nos/nas alunas e alunos. Elas e eles [...] podem indicar às professoras, pedagogas e psicólogas as pistas para a solução. (PROF. 1). 
Esse depoimento dá indicativo do predomínio por parte dos estudantes de se voltar mais ao acúmulo de informação em vez de produzir sabedoria e conhecimento. Tal conjuntura deixa entrever que esses sujeitos pouco se permitem ser influenciados por uma cultura que os atravesse e, em grande medida, perpasse a sua forma de pensar, sentir e agir. Dessa forma, a subjetivação também passa pelo que se dá na instituição, tendo em vista que o sujeito só pode ser pensado à medida que se situa nas suas referências de lugares e relações concretas que estabeleceu (PRATTA, 2008).

E, como aponta o professor, "empatia" e "construção solidária" podem ser a via para se elaborarem os possíveis resgastes da falta de sentido que leva o estudante a deixar em segundo plano a escola e se envolver com outras atividades fora dela. Nesse sentido, a retomada da afetividade enquanto elemento epistemológico do conhecimento de nós e do que está ao nosso redor possibilita que o ser humano possa se reconhecer como tal e, assim, gerar uma cultura de vida esperançosa e digna (NICOLESCU, 2008).

Por conseguinte, cabe considerar a relevância de a escola refletir sobre a realidade contemporânea, assim como a possibilidade de uma educação configurada de forma ética e responsável que permita renovar a esperança no futuro do planeta e no ser humano, conforme é ponderado na narrativa a seguir:

Mas acredito [...] que a escola deve retomar seu papel como indicador de futuro. O futuro projeto no século XX não é o mesmo do século XXI. Houve uma ruptura drástica entre as formas de viver e suas expectativas. A dimensão linear desse tempo também não é a mesma. [...] Sem dúvida temos que criar um ambiente de aprendizagem que reconheça essa dimensão e dialogue com ela. (PROF. 1).

A colocação acima dá indicativo da necessidade de se levar em consideração um novo referencial educacional que favoreça o pleno desenvolvimento do ser humano e, como especifica Suanno (2010), faz-se oportuno redimensionar paradigmas e métodos de investigação científicos para assim recriar a escola, bem como o seu papel de formar, comunicar e emocionar pessoas. Isso porque o conceito de homem centrado na dimensão racional, que tem a educação voltada a dar conta desse aspecto por descender do paradigma cartesiano, apartou a razão do sentimento, o conhecimento do afeto, a alma do corpo e, em razão disso, refreou a possibilidade de mudança de foco do pensar e do sentir, do olhar e do agir, do relacionar e do conviver consigo, com os outros e com o mundo (MORIN, 2013).

Ao se falar em uma educação que promova todas as dimensões do ser humano como condição para o resgate de uma cultura de vida, há de se considerar a abertura ao diálogo entre a mudança e o imutável. Depreende-se daí um modelo de ensino que seja holístico no que se refere a propostas, estratégias e sistemáticas de avaliação, com abertura para refletir e propor práticas inovadoras que fomentem a ressignificação da dinâmica institucional. Na perspectiva de Yus (2002), a educação numa abordagem holística visa a um processo formativo que permita equilibrar e dinamizar os conteúdos e os processos, a aprendizagem e a avaliação, e o pensamento analítico e o criativo. Essa perspectiva tem como escopo o desenvolvimento pessoal global, considerando as dimensões (físicas, emocionais e espirituais) do aprendiz. Reconhece-se a importância de se revisitar e atualizar o projeto pedagógico, a proposta curricular, os métodos de ensino, os instrumentos avaliativos. E é nesse sentido que consideramos a razoabilidade do relato a seguir:

Sem dúvida, devemos repensar as divisões e construir mais integrações curriculares, de espaço, de classes sociais no ambiente de aprendizado. [...] deixar de acreditar que apenas a disponibilidade de internet, computador, projetor ou google classroom criará um ambiente de aprendizagem efetivo. E tenho confiança que é possível à escola e seus integrantes voltar a oferecer, sobretudo para os anos finais de formação, sentidos e caminhos às vidas dos seus/ das suas estudantes. (PROF. 1).

Com efeito, estar disponível para viver experiências por meio de interações e de trocas dá indicativo de ser mais significativo do que a exposição intelectual acerca de qualquer tema, posto que os estudantes demandam a elaboração de conteúdos internos e externos. Acentuamos, em vista disso, a narrativa a seguir, quando a professora entrevistada declara que: "Atividades colaborativas são essenciais para o desenvol- 
vimento de competências socioemocionais, pois geralmente os diversos olhares demandam argumentos, posicionamentos e resolução de conflitos e ainda saber escutar o outro e respeitar opiniões" (PROF. 2).

Evidencia-se com o referido trecho que a possibilidade de se lançar a experiências dessa ordem, desapegando de maneiras antigas de pensar sobre uma dada realidade, configura-se como forma de produção de um conhecimento singularizado que oportuniza ao estudante compreender a si mesmo, como também projetar quem ele quer ser no futuro e estabelecer o seu papel no mundo. A exemplo disso, reconhecemos ser essencial a criação de momentos de integração do corpo, da mente e do espírito, através de atividades de relaxamento, de concentração, de atenção às emoções, também nesse período de finalização da educação básica. Momentos esses amorosos, não competitivos, facilitadores de preciosas experiências cognitivo-emocionais e sociais que motivem ao autoconhecimento e à autoformação. E, nessa lógica, o relato coaduna com a ideia de Bondía (2002), que descreve a experiência como algo que nos passa, toca e acontece, produzindo assim um corte nessa busca voraz por informação. Tal corte permite parar para pensar, olhar, escutar e sentir mais devagar; isso requer entrega, mesmo que momentânea, e nos tira do lugar, desvia e nos obriga a nos reinventarmos.

Sob outra perspectiva, o relato também viabiliza considerar a assertiva de Moraes (2007) sobre a atitude empática na relação entre o professor e os estudantes. Para a mencionada autora, a organização de ambientes agradáveis e efetivos de aprendizagem, onde os estudantes sintam-se acolhidos e compreendidos, abre novas possibilidades de ação perante os problemas apresentados em sala, na escola, na disciplina curricular, assim como nos problemas apresentados fora do contexto escolar.

Um aspecto interessante a considerar quanto a esse tipo de ambiente de aprendizagem é que ele possa se constituir como um local de interdependência e de colaboração, para além de ensinar, que seja capaz de criar condições para o aprender. Esse enfoque ganha relevo nos depoimentos a seguir:

É importante abandonar a narrativa centrada no professor e dar voz ao estudante para então promover debates e discussões que possam enriquecer seu repertório acadêmico, cultural e social. Enfim, utilizar o conteúdo conceitual como ponte para fazer o estudante perceber o mundo que está ao seu redor com mais criticidade, dando a ele um papel mais ativo para que não receba as informações do seu meio social de forma neutra ou ingênua. (PROF. 2).

[...] ao finalizar a educação básica esta/este discente deve ter domínio dos instrumentos para exigir/exercer a cidadania e conseguir gerir com crescente autonomia a sua própria vida. (PROF. 1).

Nessa lógica, convém destacar o indicativo de destituição da posição do professor como único detentor do saber e a reconfiguração da relação educativa com o estudante através da partilha desse reconhecido lugar de fala e produção do saber. É no conviver como ser humano de linguagem, cooperativo, amoroso, respeitoso, consciente de si e do outro que ambos coevoluem. Diante do exposto, consideramos relevante a interface entre o lugar de fala e o posicionamento de Freire (1996) ao defender a pertinência do silêncio na comunicação, posto que a cedência da fala ao outro demanda atenção e escuta sensível ao que está sendo dito para que a fala comunicante entre no movimento interno de pensamento de outrem, convertendo-se em linguagem.

Também cabe sublinhar nos relatos acima o olhar atento do professor em identificar as necessidades apresentadas pelos estudantes e convertê-las em subsídios para a atividade de ensino e de aprendizagem que promova um saber ético, crítico, construtivo e atualizado. De acordo com Freire (2007, 2012), a educação problematizadora desafia a criação de espaços para o pleno exercício e vivência da autonomia e da cidadania através da assunção pelo professor de uma postura de mediação entre o estudante e o objeto do conhecimento. Nessa conjuntura, professor e estudantes se reconhecem como seres históricos e sociais ao discutirem o conteúdo no sentido social, ideológico e político, possibilitando, assim, criar uma forma de transformação da realidade. 


\section{Conclusões}

A mudança por que passa a sociedade contemporânea - embasada por um paradigma civilizatório que valoriza a apropriação, o acúmulo e o consumo, põe em risco nossa sobrevivência e tem nos levado a um vazio existencial - ao atravessar o âmbito educacional, requer uma reflexão a respeito de como os sujeitos escolares têm lidado com tal conjuntura, sobretudo no contexto de finalização da educação básica.

Verifica-se, pois, que a passagem do Ensino Médio ao Ensino Superior tem sido marcada por expectativas quanto ao projeto de vida envolvendo a escolha de uma profissão e torna-se, de forma isolada, a única previsão para adentrar o mercado de trabalho. Reduz-se, assim, essa etapa da educação a preparação para o vestibular, o que reforça, no contexto contemporâneo, um grande estímulo à cobrança de alto desempenho e à competição, refletindo nos jovens um sentimento de impotência e crises de ansiedade. Nesse quadro, ausentar-se do espaço escolar para assumir o compromisso com outros espaços de estudo tornou-se uma alternativa encontrada pelos estudantes com vistas a garantir o futuro gestado em parceria com as famílias.

A falta de sentido que a escola parece ter para os estudantes por não conseguir atender as suas perspectivas robustece a ideia de que é a escola, ainda, a via que vai de encontro a tal lógica quando prima pela promoção da formação humana. Destaca-se, dessa maneira, a afetividade na relação pedagógica como possibilidade de prática que permita o reconhecimento e a vivência desse período formativo com fim em si mesmo, ou seja, o desenvolvimento que perpasse a forma de pensar, sentir e agir.

Mediante essa realidade, entendemos ser preciso tecer uma educação que nos permita não apenas conhecer e fazer, mas também ser e conviver. Sonhar e criar novos valores, de modo que cada um possa oferecer o que tem de melhor, com a finalidade de idealizar e configurar novas visões de mundo mais coerentes e sustentáveis em relação ao desenvolvimento da vida. Para tanto, esse ambiente educacional precisa ser compreendido e planejado como espaço conversacional atravessado por diferentes e pertinentes conteúdos e informações que circulam entre os sujeitos escolares.

Por conseguinte, esperamos que as reflexões aqui ventiladas possam contribuir para futuros debates nas escolas que pretendem situar-se enquanto espaços de interações biopsicossociais, ademais, culturais, políticos e espirituais que promovam a aprendizagem abrangendo as diferentes dimensões humanas.

\section{Referências}

ALMEIDA, Gisele Gomes. Sentidos compartilhados sobre o Colégio de Aplicação da UFPE: um estudo com pais e estudantes. 2014. 285 f. Dissertação (Mestrado em Educação) - Universidade Federal de Pernambuco, Recife, 2014. Disponível em: https://repositorio.ufpe.br/bitstream/123456789/12997/1/TESE\%20Gisele\%20Gomes\%20de\%20Almeida.pdf. Acesso em: 26 maio 2020.

APLICAÇÃO da UFPE é a segunda melhor escola da rede pública do Brasil. Diário de Pernambuco, Recife, 6 jul. 2020. Disponível em: https://www.diariodepernambuco.com.br/noticia/vidaurbana/2020/07/aplicacao-da-ufpe-e-a-segunda-melhor-escola-da-rede-publica-do-brasil.html. Acesso em: 24 jul. 2020.

BARDIN, Laurence. Análise de conteúdo. São Paulo: Edições 70, 2011.

BOTLER, Alice Miriam Happ; SILVA, Viviane Alves de Lima. Desigualdade de oportunidades: "injustiças democráticas" em colégios de aplicação. Revista Profissão Docente, Uberaba, v. 19, n. 41, p. 1-17, maio/ago. 2019. Disponível em: http://www.revistasdigitais.uniube.br/index.php/rpd/article/view/1295. Acesso em: 28 maio 2020.

COLÉGIO DE APLICAÇÃO DA UFPE. Projeto pedagógico do Colégio de Aplicação da UFPE. Recife: UFPE, 2016. Disponível em: https://www.ufpe.br/documents/39038/0/PP+CAp+mar\%C3\%A7o+2020.pdf/cb5990b2-55ed-41df-b35a-9913c738bd47. Acesso em: 28 maio 2020.

D’ÁVILA, Gerusa Tavares; SOARES, Dulce Helena Penna. Vestibular: fatores geradores de ansiedade na "cena da prova”. Revista Brasileira de Orientação Profissional, São Paulo, v. 4, n. 1/2, p. 105-116, dez. 2003. Disponível em: http://pepsic.bvsalud.org/scielo.php?script=sci_arttext\&pid=S1679-33902003000100010. Acesso em: 25 jul.2020.

DUARTE, Rosália. A entrevista em pesquisa qualitativa. Educar em Revista, Curitiba, v. 20, n. 24, p. 213-225, 2004. Disponível em: https://www.scielo.br/pdf/er/n24/n24a11.pdf. Acesso em: 14 jun. 2020. 
FREIRE, Madalena (org.). Observação, registro, reflexão: instrumentos metodológicos I. 2. ed. São Paulo: Espaço Pedagógico, 1996.

FREIRE, Paulo. Pedagogia da autonomia: saberes necessários à prática educativa. 36. ed. São Paulo: Paz e Terra, 2007.

FREIRE, Paulo. À sombra desta mangueira. São Paulo: Olho d’Água, 2012.

HAN, Byung-Chul. Sociedade do cansaço. Tradução de Enio Paulo Giachini. Petrópolis: Vozes, 2015.

BONDÍA, Jorge Larrosa. Notas sobre a experiência e o saber da experiência. Revista Brasileira de Educação, Rio de Janeiro, n. 19, p. 20-28, jan./abr. 2002. Disponível em: https://www.scielo.br/pdf/rbedu/n19/n19a02.pdf. Acesso em: 3 jun. 2020.

MARQUES, Janote Pires. A observação participante na pesquisa de campo em Educação. Educação em Foco, Belo Horizonte, v. 19, n. 28, p. 263-284, mai./ago. 2016. Disponível em: http://revista.uemg.br/index.php/educacaoemfoco/article/view/1221. Acesso em: 10 jun. 2020.

MORAES, Maria Cândida. A formação do educador a partir da complexidade e da transdisciplinaridade. Diálogo Educacional, Curitiba, v. 7, n. 22, p. 13-38, set./dez. 2007. Disponível em: https://www.redalyc.org/pdf/1891/189116805002.pdf. Acesso em: 3 jun. 2020.

MORIN, Edgar. Os sete saberes necessários à educação do futuro. 1. ed. São Paulo: Cortez; Brasília, DF: UNESCO, 2013. MORIN, Edgar. O método V: a humanidade da humanidade. Porto Alegre: Sulina, 2012.

NASCIMENTO, Antônio Dias; HETKOWSKI, Tânia Maria (org.). Educação e contemporaneidade: pesquisas científicas e tecnológicas. Salvador: EDUFBA, 2009.

NICOLESCU, Basarab. Manifesto da transdisciplinaridade. 3. ed. São Paulo: Triom, 2008.

PEREIRA, Maria José de Araújo; GONÇALVES, Renata. Afetividade: caminho para a aprendizagem. Revista Alcancead, Rio de Janeiro, v. 1, n. 1, p. 12-19, 2010. Disponível em: https://docplayer.com.br/18440848-Afetividade-caminhopara-a-aprendizagem.html. Acesso em: 25 jul. 2020.

PRATTA, Márcia Aparecida Bertolucci. Adolescentes e jovens... em ação! Aspectos psíquicos e sociais na educação de adolescentes hoje. São Paulo: Editora UNESP, 2008.

ROSENBURG, Eleusa Gallo. O impacto das vivências de psicologia realizadas nos meses que antecedem ao vestibular. Revista em Extensão, Uberlândia, v. 5, n. 1, p. 19-29, 2005-2006. Disponível em: https://sumarios.org/artigo/oimpacto-das-viv\%C3\%AAncias-de-psicologia-realizadas-nos-meses-que-antecedem-ao-vestibular. Acesso em: 25 jul. 2020.

SANTROCK, John. Adolescência. 14. ed. Porto Alegre: AMGH, 2014.

SOUZA, Rogério Gonçalves; BASTOS, Sandra Nazaré Dias. Discursos epistemológicos de afetividade como princípios de racionalidade para a educação científica e matemática. Revista Ensaio, Belo Horizonte, v. 13, n. 3, p. 169-184, 2011. Disponível em: https://www.scielo.br/pdf/epec/v13n3/1983-2117-epec-13-03-00169.pdf. Acesso em: 6 maio 2020.

SPARTA, Mônica; GOMES, William. Importância atribuída ao ingresso na educação superior por alunos do Ensino Médio. Revista Brasileira de Orientação Profissional, São Paulo, v. 6, n. 2, p. 45-53, dez. 2005. Disponível em: http:// pepsic.bvsalud.org/scielo.php?script=sci_arttext\&pid=S1679-33902005000200005. Acesso em: 20 jun. 2020.

SUANNO, José Henrique. Práticas inovadoras em educação: uma visão complexa, transdisciplinar e humanística. In: MORAES, Maria Cândida; NAVAS, Juan Miguel Batalloso (org.). Complexidade e transdisciplinaridade em educação: teoria e prática docente. Rio de Janeiro: Wak Editora, 2010. p. 207-226.

UNIVERSIDADE FEDERAL DE PERNAMBUCO (UFPE). Colégio de Aplicação tem excelente resultado no Enem 2018. UFPE: Recife, 2019. Disponível em: https://www.ufpe.br/agencia/noticias/-/asset_publisher/dlhi8nsrz4hK/content/ colegio-de-aplicacao-tem-excelente-resultado-no-enem-2018/40615. Acesso em: 27 maio 2020.

UNIVERSIDADE FEDERAL DE PERNAMBUCO. Resolução no 14/2016, de 14 de julho de 2016. Estabelece critérios para o processo seletivo de ingresso no Colégio de Aplicação do Centro de Educação da UFPE. Boletim Oficial da UFPE, Recife, v. 51, n. 69 (especial), p. 17-20, 14 jul. 2016. Disponível em: https://www.ufpe.br/documents/38962/1143245/bo+\%2869\%29.pdf/. Acesso em: 8 jun. 2020.

YIN, Robert K. Estudo de caso: planejamento e métodos. 3. ed. Porto Alegre: Brookman, 2005.

YUS, Rafael. Educação integral: uma educação holística para o século XXI. Porto Alegre: Artmed, 2002.

Data de submissão: 30/06/2020

Data de aceite: $27 / 07 / 2020$ 